\title{
ÉTIENNE DOLET E O "MODO DE TRADUZIR BEM DE UMA LÍNGUA A OUTRA"
}

\author{
Mauri Furlan \\ Universidade Federal de Santa Catarian \\ maurizius@gmail.com
}

\begin{abstract}
Resumo: Considerado "o único programa formal de teoria da tradução na França renascentista” (Norton 1984: 103), o clássico texto de Étienne Dolet, La manière de bien traduire d'une langue en autre (1540), é aqui analisado em sua estrutura e conteúdo, com algumas indicações do pensamento constituidor subjacente, formado pela teoria da retórica clássica, compreendida como a concepção da linguagem então vigente no século XVI.
\end{abstract}

Palavras-chave: Étienne Dolet, Renascimento, teoria da tradução.

\begin{abstract}
Considered "the only formal program of translation theory in Renaissance France" (Norton 1984: 103), the classic text by Étienne Dolet, La manière de bien traduire d'une langue en autre (1540), is herein analyzed in its structure and content, accompanied with a few remarks on its underlying thought, formed by the classical rhetorical theory, understood as the conception of language then in force in the 16th century.
\end{abstract}

Keywords: Étienne Dolet, Renaissance, translation theory.

Étienne Dolet (1509-1546) é considerado “el epónimo y patriarca de la traducción francesa” (Vega 1994: 722), o que principia a reflexão teórica sobre a tradução em seu país e introduz as palavras 'traduction' e 'traducteur' na língua francesa (DelisleWoodsworth 1995: 277), e o que, "injustamente", é apontado pelos especialistas franceses como o primeiro tradutólogo moderno (Vega 1997: 73). "Escritor, traductor, poeta, defensor de la razón” (López Carrillo 1998: 69), natural de Orléans, estudou humanidades clássi- 
cas em Paris e em Pádua, e direito em Toulouse. Sua grande liberdade de pensamento e agudeza crítica lhe deram a fama e a morte. Dolet foi uma figura polêmica, com grandes amigos e inimigos, perseguido por questões políticas e religiosas. Foi secretário do bispo de Limoges, Jean de Langeac (Jean du Bellay), conseguiu o apoio de personalidades religiosas (Jean de Pins, bispo de Rieux; Pierre Duchatel, bispo de Tulle) e pertenceu à elite cultural francesa do Renascimento (Jean de Boyssone, Sébastien Gryphius, Guillaume Budé, François Rabelais, Clément Marot...). O rei Francisco I lhe concedeu, em 1538, "el privilegio de impresor para cualquier libro que compusiera, tradujera, revisara, anotara o corrigiera en latín, griego, italiano y francés" (López Carrillo 1998: 18). Assim o fez, publicando em latim ou em língua vulgar suas obras e traduções, e de outros autores. Em 1546, encarcerado pela quinta vez e condenado, foi estrangulado antes de ser queimado junto a seus livros como ateu e blasfemo. Convertia-se, assim, em um dos "mártires do Renascimento". Dentre uma dezena de títulos, sua obra mais importante é um dicionário etimológico latino, Commentariorum linguae latinae epitome, 1536-38. Deixou inconcluso o projeto de um grande trabalho sobre a língua francesa, o Orateur françoys, uma obra que, pretendia seu autor, estimularia os escritores a utilizarem a língua francesa em lugar do latim, valendo como uma propedêutica que ensinasse a escrire bien, bien tourner, \& bien dire [escrever bem, traduzir bem \& falar bem]. Publicou apenas três das nove partes previstas, sendo a primeira o texto que analisamos aqui: $L a$ maniere de bien traduire d'une langue en aultre, $1540^{1}$. Os outros dois textos se intitulam D'advantage de la punctuation de la langue Françoyse, Plus des accents d'ycelle. A repercussão destes textos deixa-se ver por sua reimpressão anual pelo próprio Dolet nos três anos seguintes à primeira edição.

De grande defensor da língua latina, Dolet passa ao reconhecimento e valorização de sua língua materna vulgar, o francês. Sua mudança ou abertura denota uma estreita conexão com a realidade 
histórico-política cambiante de seu tempo. No século XVI francês, como ocorria na Itália e em outras regiões, amplia-se em muito o universo leitor, que deseja textos em sua língua materna. Com o crescente nacionalismo e após a promulgação pelo rei Francisco I, em 1539, do edito de Villers-Cotterêts, que impunha a substituição do latim pela língua francesa nos textos oficiais - e que vai afetar toda a sociedade francesa, cujos intelectuais escreviam em latim , Dolet, no espírito de sua época - "Mon affection est telle envers l'honneur de mon pays que je veux trouver tout moyen de l'illustrer" [meu afeto pela honra de meu país é tão grande que busco encontrar qualquer meio de ilustrá-lo], escreve no prefácio a sua Maniere - estabelece o projeto de uma obra que formalize e difunda o francês como um idioma que apresenta os mesmos valores que as línguas clássicas ou outras modernas como o italiano. Seu projeto propunha uma unificação da língua vulgar, e nele a tradução recebe o status de co-formadora da cultura nacional ao oferecer em língua romance as obras gregas e latinas tornadas literatura francesa, em bom francês. O latim e o grego continuavam sendo o principal parâmetro de avaliação das novas línguas vulgares, tanto no concernente a sua cultura lingüística como literária, e a tradução era um meio de apropriação destes valores. A boa tradução se apresentava, assim, como imprescindível por seu papel de mediadora cultural lato sensu, ou seja, não apenas relativa ao conhecimento de outras sociedades mas como escritura-literatura que participa na construção da língua vernácula: "La traduction est donc devenue une cause nationale" [A tradução tornou-se, pois, uma causa nacional] (Chavy 1981: 291). A má tradução colocaria em perigo o bom desenvolvimento da língua de chegada, de forma que, uma preceptiva da tradução poderia salvaguardar sua uniformidade e propriedade lingüísticas. Esta noção é clara em Dolet, como o demonstra o fato de que a seu texto sobre a tradução acompanham outros dois sobre regras ortográficas.

La maniere de bien traduire d'une langue en aultre, de 1540, é, segundo Norton, "the only formal program of translation theory in 
Renaissance France" [o único programa formal de teoria da tradução na França do Renascimento] (1984: 103). De uma forma altamente objetiva e sintética, Dolet expõe em cinco pontos sua concepção teórico-prática da tradução. O processo tradutório começa com uma análise profunda sobre o objeto a traduzir (compreensão do sentido, do autor, e conhecimento da matéria). O conhecimento de ambas línguas e suas propriedades, com as quais o tradutor trabalha, impelem-no a um tipo de tradução de tendência livre, no qual deve privilegiar a língua de chegada com a preservação de suas propriedades ${ }^{2}$. Por fim, o tradutor-autor, servindo-se dos recursos retóricos que oferece a língua de chegada, reconstruirá "criativamente' no produto final os elementos anteriormente desconstruídos ${ }^{3}$ por meio da compreensão do sentido.

\section{Estrutura do texto}

O pequeno ensaio de Dolet sobre a tradução - 6 páginas na edição fac simile de Lyon, 1540 - é o primeiro dos textos que deveriam compor a obra maior, Orateur françoys, que ficou inconclusa. O programa da obra constava de nove partes: 01. La grammaire, 02. L'orthographe, 03. Les accents, 04. La punctuation, 05. La pronunciation, 06. L'origine d'aulcunes dictions, 07. La maniere de bien traduire d'une langue en aultre, 08. L'art oratoire, 09. L'art poétique, das quais Dolet somente chegou a editar três, as concernentes à tradução, acentuação e pontuação. $O$ fato de haver começado a publicar sua obra com o texto sobre a tradução é reflexo da importância que a questão ocupava então na França em meio a polêmicas sobre $\mathrm{o}$ valor, a necessidade e os perigos que a tradução representava no contexto do estabelecimento da língua francesa enquanto identidade nacional.

A reflexão sobre a tradução principia ex abrupto, sem qualquer definição da $a r s^{4}$ de traduzir. Começa assim: 
La manière de bien traduire d'une langue en autre requiert principalement cinq choses. (Dolet, 2006: 198)

Traduzir bem de uma língua a outra requer principalmente cinco coisas.

E seguem as cinco regras:

1. Compreender o sentido e o tema do autor que é traduzido * exemplo: Questões Tusculanas, de Cícero;

2. Conhecer perfeitamente a língua do autor que é traduzido e a língua em que é traduzido

* reconhecimento das propriedades de cada língua;

3. Traduzir ad sententiam

* a torpeza da tradução ad uerbum;

4. Utilizar a língua comum

* hierarquia das línguas;

* uso de palavras comuns e não demasiado próximas

do latim;

* cuidado com as inovações;

5. Observar a harmonia do discurso (a cadência oratória)

* uso dos ouvidos;

* a harmonia é o principal de uma escritura;

* harmonia, eloqüência, frases e argumentos.

Na estruturação e composição de seu pentálogo, Dolet foi extremamente objetivo, sucinto e didático. Seus preceitos partem do objeto a traduzir e seus requisitos (conhecimento do autor, obra, tema e línguas), passam pelos meios a empregar e o tipo de tradução mais recomendável (tradução ad sententiam e o uso da língua comum) e chegam ao produto final com seus valores retórico-literários (harmonia do discurso). 


\section{Conteúdo do texto}

A dedicatória ao Senhor de Langey (Guillaume du Bellay, 14911453) - um nobre, general do rei Francisco I, diplomático, escritor e protetor das ciências e das artes - e a carta ao povo francês constituem mais do que meras formalidades editoriais; nelas o autor revela algo de sua posição política enquanto cidadão francês, seu desejo de contribuir na construção da língua nacional e de formar o povo, sua frustração com os homens de seu tempo, e o programa geral do Orateur françoys. Nestas páginas introdutórias apresenta um estilo mais livre, pessoal e retórico do que o de seu ensaio sobre tradução. Começa a dedicatória esclarecendo os dois motivos que o levaram a escrever a presente obra, uma vez que no passado se havia dedicado exclusivamente à língua latina: primeiro, o amor ao seu país, ao qual celebra honrando sua língua materna, como o fizeram os gregos e romanos com as suas; e depois, a exemplo de alguns italianos e franceses. Seu objetivo é participar no labor que deve impulsar a língua francesa à mesma perfeição que as línguas clássicas, pela qual "les estrangiers ne nous appelleront plus Barbares" [os estrangeiros não nos chamarão mais de bárbaros]. Esta contribuição se efetivaria na instrução lingüística do povo por meio de regras lingüísticas e retóricas gerais, entre as quais se encontra a tradução, que é concebida como um grande exemplo que, como a literatura, conjugaria o uso da gramática e da retórica.

É surpreendente a semelhança dos cinco pontos estabelecidos por Dolet em sua reflexão sobre a tradução com o pensamento, acerca da tradução, de outros pensadores contemporâneos como Martinho Lutero e Juan Luis Vives. Tendo publicado seu texto em 1540, não sabemos se Dolet teria lido Sendbrief vom Dolmetschen, de Lutero, 1530, ou Versiones seu interpretationes, de Vives, 1533, mas certamente conhecia e bem o texto de Bruni, De recta interpretatione, $1420^{5}$, pois, em sua exposição, retoma e reescreve a reflexão do Aretino, segundo nossa leitura das cinco regras, que 
confirmamos nas palavras de E. Mattioli (1982: 46): "In sostanza Doleto riprendi a Bruni" [Em substância, Dolet retoma Bruni]. Ou seja, as idéias fundamentais de Dolet não são criação sua, mas aparecem por primeira vez sintetizadas no Renascimento europeu no texto bruniano, especialmente a concepção de tradução literária, artística.

I. Mesmo sem definir explicitamente a tradução, o primeiro ponto de seu ensaio reflete sua concepção e oferece o ponto de partida do processo tradutório: "entendre parfaitement le sens et matière de l'auteur qu'il traduit" [compreender perfeitamente o sentido e o tema do autor que traduz] (2006: 198). Assim como a de Bruni, é uma concepção hermenêutica da tradução, pois supõe uma interpretação correta do original. Mais sutil, no entanto, que Bruni, dá ênfase à compreensão do 'sentido' - como fez Vives -, do 'tema' ou matéria, e do 'autor' - como fez Lutero. Dolet parece independizar de sua língua original o conteúdo a ser traduzido. Claro que a compreensão do sentido do original não se realiza sem o conhecimento da língua de partida, porém este conhecimento por si só não garante dita compreensão do sentido. O tradutor deverá dedicar-se ao estudo da obra a traduzir não só lingüística mas filologicamente e ainda mais, monograficamente, ou seja, conhecendo a matéria de que o autor trata e o próprio autor em sua singularidade e com suas características. Para Edmond Cary, o fato de que Dolet tenha posto este princípio antes daquele do conhecimento das línguas indica a primazia do conteúdo do texto a traduzir sobre a forma lingüística (1963: 9); enquanto que Norton classifica de "curioso" o fato de que Dolet apresente um padrão de eventos aparentemente invertido (1984: 207). Recorde-se que para Bruni, por exemplo, as habilidades lingüísticas (peritia linguarum) - o domínio da língua de partida e o domínio da língua de chegada - legitimam e precedem o ato de análise textual do tradutor. López Carrillo, por sua vez, entende que "el sentido es la base de la comprensión y es determinado por el tema y el autor” (1998: 77). O tema ou matéria 
em que se expressa o autor é um elemento que reflete um ponto de vista pessoal, cuja chave de compreensão é o próprio autor. O exemplo argumentativo oferecido por Dolet é muito ilustrativo. Citando um pensamento de Cícero, propõe uma tradução:

Animum autem animam etiam fere nostri declarant nominari. Nam et agere animam, et effare dicimus: et animosos, et bene animatos: et ex animi sententia. Ipse autem animus ab anima dictus est (Cícero, Tusculanae disputationes, I, IX, 19, apud Dolet, 2006: 198). ${ }^{6}$

Quant à la différence de ces dictions, animus et anima, il ne s'y faut point arrêter, car les façons de parler latines qui sont déduites de ces deux mots, nous donnent à entendre qu'ils signifient presque une même chose. Et est certain que animus est dit de anima, et que anima est l'organe de animus: comme si tu voulais dire la vertu et instruments vitaux être origine de l'esprit, et icelui esprit être en effet de la dite vertu vitale (Dolet, 2006: 198).

Quanto à diferença das palavras animus e anima não é preciso nos determos, pois os modos de dizer latinos que dela são deduzidos nos dão a entender que significam quase a mesma coisa. E é certo que animus é dito de anima e que anima é o órgão de animus, como se você quisesse dizer serem a virtude e os instrumentos vitais a origem do espírito e ser este um efeito da mesma virtude vital. (trad. de Goldstein \& Bonatti, in Dolet 2006: 199).

Tusculanae é uma obra filosófica, e Dolet cita precisamente uma passagem de Cícero de difícil tradução ${ }^{7}$. No entanto, sua tradução é uma verdadeira 'interpretação', um comentário que se baseia no sentido, ad sententiam, o que só foi possível porque o tradutor conhecia a matéria e o autor. A compreensão do sentido, para Dolet, é o requisito básico para a produção de uma versão 
'fiel' e 'segura'. O tradutor que consiga "cette intelligence il ne sera jamais obscur en sa traduction" [esta compreensão nunca será obscuro em sua tradução] (2006: 198).

Ao advertir sobre a necessidade de ter conhecimentos da matéria, do sentido e do autor, Dolet está retomando o grande princípio da retórica clássica, fundamental na elaboração de cada discurso. A matéria é a primeira das partes que compõem um tratado de retórica. Toda obra de arte por meio da palavra consta de res [coisas] e de uerba [palavras]. O estudo da matéria é o estágio inicial da res, a primeira das fases elaborativas do discurso.

López Carrillo (1998) interpreta e esquematiza a teoria da tradução de Dolet no trinômio Objeto-Processo-Produto, no qual o Objeto, correspondendo à primera regra (compreensão do autor, tema e sentido), equivale aos elementos implicados no conteúdo da obra a traduzir; o Processo fundiria a segunda, a terceira e a quarta regras (conhecimento das línguas, tradução ad sententiam, e uso de palavras comuns), equivalendo ao processo mediador entre o Objeto e o Produto; e o Produto, fundamentado na quinta regra (a harmonia do discurso), referir-se-ia ao texto final da tradução. Salvaguardando sua concepção básica, utilizamos aqui mais livremente este trinômio. Esta separação de elementos que compõem um todo é, antes de tudo, didática, e corresponde à divisão proposta por Dolet e à concepção de linguagem então vigente, com seus padrões de ‘construção' e 'desconstrução' das partes.

II. O perfeito conhecimento de ambas línguas é a segunda regra de Dolet. Esta exigência para o bem traduzir se apresenta em praticamente todas as reflexões tradutológicas posteriores ao tratado de Bruni, embora não tenha sido ele o primeiro a reclamar tal requisito. É interessante observar que Dolet pede ao tradutor que possua o conhecimento perfeito de ambas línguas ao mesmo tempo, sem privilegiar um maior conhecimento de uma língua sobre o de outra, o que, com efeito, constituía um debate em sua época: deveria o tradutor conhecer mais a língua da qual traduz ou aquela para a qual traduz? Este é um detalhe histórico, porém muito im- 
portante porque também ajuda a justificar a presença de um enunciado como este, no pentálogo doletiano, que não chega a ser entendida por alguns pesquisadores contemporâneos, como Paul Chavy (1981), dada sua aparente obviedade.

"Chacune langue a ses propriétés, translations en diction, locutions, subtilités et véhémences à elle particulières" [Cada língua tem suas propriedades, suas expressões metafóricas, suas locuções, sutilezas e vehemências que lhe são características] (2006: 200). Para discernir os traços característicos de cada língua, o tradutor, entende Dolet, deverá servir-se de sua peritia linguarum [domínio das línguas], para retomar aqui o termo usado por Leonardi Bruni. A ignorância das diferenças entre as línguas pode prejudicar o autor que é traduzido e também a língua da tradução, ensombrecendo "la dignité et richesse de ces deux langues desquelles il prend le maniement" [a dignidade e riqueza destas duas línguas que [o tradutor] está manejando] (2006: 200).

Depois de tratar do objeto, Dolet expõe a primeira das três regras que cuidarão diretamente do processo tradutório. O conhecimento das línguas é um instrumento de trabalho do tradutor. Enquanto processo, o domínio da língua de partida permite ao tradutor desconstruir o objeto através da compreensão, e o domínio da língua de chegada permite reconstruí-lo para sua reprodução no produto final. Uma vez compreendido o sentido, o tradutor deverá refletir sobre as propriedades das duas línguas envolvidas para passar corretamente dito sentido ao novo texto. Ademais da fidelidade ao sentido original, o tradutor deve procurar não violar nem diminuir "la majesté de l'une et l'autre langue" [a grandiosidade de nenhuma das duas línguas] (2006: 200): "transgression against the text is seen as inseparable from transgression against language" [a transgressão do texto é vista como inseparável da transgressão da linguagem] (Norton 1984: 207).

III. A conservação cuidadosa da propriedade de ambas línguas é o objetivo da terceira regra, a da tradução ad sententiam - Dolet não utiliza esta expressão latina -. O reconhecimento das proprie- 
dades de cada língua com suas características singulares impulsará o tradutor inevitavelmente a um tipo de tradução, aquele $a d$ sententiam, por meio da qual tentará manter as propriedades de ambas línguas. No terceiro princípio, o humanista advoga em favor da liberdade da tradução e do tradutor, e propõe o mesmo princípio para a tradução em prosa e em verso. Dadas as diferenças entre as línguas, é inviável a tradução palavra por palavra, pois neste tipo de tradução o tradutor seria presa do texto com suas estruturas na língua de partida, não poderia alcançar sua reprodução total nem sequer seu sentido, e não respeitaria o gênio da língua de chegada. A terceira regra, estreitamente vinculada à segunda, reza que o tradutor não deve "asservir jusques à là que l'on rende mot pour mot" [submeter-se ao texto até o limite de traduzir palavra por palavra], mas que, na tradução ad sententiam, o tradutor

sans avoir égard à l'ordre des mots il s'arrêtera aux sentences, et fera en sorte que l'intention de l'auteur será exprimée, gardant curieusement la propriété de l'une et l'autre langue (Dolet 2006: 200).

deter-se-á nas sentenças sem considerar a ordem das palavras, e fará de tal forma que a intenção do autor será expressa, conservando cuidadosamente a propriedade de cada língua (trad. de Goldstein \& Bonatti, in Dolet 2006: 201).

A submissão às palavras do texto original revela ignorance [ignorância], pauvreté [pobreza], défaut d'esprit [falta de engenho] e ausência dos requisitos necessários ao bom tradutor. Com a tradução ligne pour ligne, ou vers pour vers [linha por linha ou verso por verso], apenas se consegue o falseamento do sens de l'auteur [sentido do autor]. Sem dúvida, esta regra é a mais importante das três que constituem o proceso de tradução, pois, na verdade, é a que determina o tipo de tradução. A tradução ad sententiam doletiana tenta recriar com liberté [liberdade] l'intention de l'auteur [a in- 
tenção do autor] e o sentido do texto, e expressar la grâce et perfection [a graça e a perfeição] de ambas línguas.

IV. A quarta regra defende na tradução o emprego do commun langage [a língua comum]. É un princípio que nos recorda die gemeine Sprache [a língua comum], de Lutero, e o usus loquendi [o falar corrente], de Vives. O commun langage de Dolet se refere às palavras e expressões já presentes e em uso na língua, $d u$ commun, a língua de domínio público e já consagrada pelo uso. Ao falar aos tradutores, Dolet está provavelmente pensando na língua dos destinatários das traduções, os que não são eruditos nem dominam línguas estrangeiras, os mesmos aos quais é dirigida sua obra e que devem instruir-se. Sua opção pelo commun langage é uma defesa da língua corrente do homem comum e uma defesa da língua francesa 'nacional', que deve afirmar-se e desenvolver-se sobre suas bases já estabelecidas, diferenciando-se definitivamente da língua latina.

O humanista recomenda que o tradutor não utilize palavras demasiado próximas do latim e pouco usadas no passado; a verdadeira tradução se produz quando as palavras podem ser escolhidas do patrimônio da língua. Percebe-se aqui uma tendência que vem desde o século XIII aproximadamente, que é o desejo de que a tradução deixe de ser latina, porém também una tentativa de fixação e aperfeiçoamento da língua já existente, com seus traços distintos da latina. A nova língua vernácula romance já não é mais a língua latina evoluída e transformada, é outra língua. Comprova-o a tradição do uso das palavras de seu próprio tesouro. A nova língua francesa ainda sofria de inferioridade sob a conhecida hierarquização das línguas, com o latim ocupando a segunda posição, depois do grego e à frente do hebraico, com as quais as novas línguas romance se comparavam, se mediam, e por elas se julgavam, porque ainda não haviam sido réduites en art, [formalizadas tecnicamente], como o estavam as clássicas. 
La quatrième règle que je veux bailler en cet endroit est plus à observer en langues non réduites en art qu'en autres. J'appelle langues non réduites encore en art certain et reçu, comme est la française, l'italienne, l'espagnole, celle d'Alemagne, d'Angleterre, et autres vulgaires. [...] On sait bien que la langue grecque ou latine est trop plus riche en dictions que la française (Dolet 2006: 200; 202).

A quarta regra que quero dar aqui deve ser mais observada em línguas não sistematizadas que em outras. Chamo de línguas ainda não sistematizadas e reconhecidas aquelas como a francesa, a italiana, a espanhola, a da Alemanha, a da Inglaterra, e outras vulgares. [...] Sabemos bem que a língua grega ou a latina são muito mais ricas em expressões que a francesa (trad. de Goldstein \& Bonatti, in Dolet 2006: 201; 203).

O emprego na tradução de palavras próximas do latim é um procedimento "néscio" (follement), "arrogante" (arrogance), "intolerável" (no tolérable), coisa de "charlatães" (babillards). No entanto, isto não significa "abstenção" (s'abstienne) total das palavras que não pertenecem ao uso comum. Ao tradutor é permitido empregar des mots peu fréquentés... à l'extrême nécessité [palavras pouco freqüentes... em casos de extrema necessidade], como apresenta-os a necessidade de tecnicismos na tradução de textos filosóficos e científicos.

A constatação de que as novas línguas vernáculas ainda não haviam alcançado a categoria de artísticas, e a recomendação do uso de palavras comuns e da língua comum diz respeito a uma operação primária na elaboração de um discurso, na teoria da retórica clássica, a electio uerborum [a escolha das palavras], que pode aqui ser analisada nos níveis da proprietas, puritas e perspicuitas [propriedade, pureza e clareza].

A referência às línguas non réduites en art [não sistematizadas], - ou seja, que ainda não têm uma estrutura analítica, que não 
foram formalizadas tecnicamente, como o foram o grego, o latim e o hebraico - alude à proprietas: as línguas enquanto proprietárias de palavras - a quantidade de palavras também é contada entre as particularidades de uma língua - . Desde que as línguas vernáculas começaram a se formar, costumava-se dividir as línguas em duas categorias, as ricas e as pobres. Para que uma língua fosse rica não bastava possuir suficiência de palavras, haveria que possuir um excesso de palavras, copia et abundantia. Na época de Dolet, a língua francesa já possuía uma quantidade razoável de palavras que a fazia desejar sair da categoria de língua pobre.

O conselho doletiano de não empregar palavras demasiado próximas do latim se refere à puritas, ou seja, as palavras que já adquiriram cidadania numa língua. A puritas deve garantir que as palavras usadas na sentença pertençam ao vocabulário comum. Entre os critérios para estabelecer a pureza das palavras se encontram uetustas, auctoritas e usus [a idade, a autoridade e o uso], critérios de que se serve Dolet quando preconiza "não empregar palavras pouco usadas no passado". Para que uma palavra seja considerada 'pura', deve estar em uso (usus), ser falada na comunidade. Também uma palavra que é velha (uetustas) deve ser considerada pura. O princípio por trás desta idéia é o fato de que uma palavra velha pertenceu em algum tempo ao usus, e que a idade não lhe tirou sua pureza. $\mathrm{O}$ uso das palavras no passado é comprovado sobretudo no emprego lingüístico dos escritores e grandes autores (auctoritas), ainda que com certos limites.

V. A última regra concerne aos nombres oratoires, a "harmonia do discurso". Se a terceira regra, a da tradução ad sententiam, pode ser considerada definidora do tipo de tradução escolhido por Dolet, a quinta é de suma importância, pois é a que faz com que o texto em produção se torne literatura, e é para o humanista francês "de si grande vertu, que sans elle toute composition est lourde et malplaisante" [de tão grande importância, que, sem ela, toda composição resulta pesada e pouco agradável] (2006: 2002). A harmonia do discurso, ou cadência oratória, consiste em 
une liaison et assemblement de dictions avec telle douceur, que non seulement l'âme s'en contente, mais aussi les oreilles en sont toutes râvies, et ne se fâchent jamais d'une telle harmonie de langage (Dolet 2006: 202).

um enlace e união das palavras com tal suavidade que não somente a alma se satisfaça, mas também os ouvidos se encantem e não se cansem jamais de uma tal harmonia de linguagem (trad. de Goldstein \& Bonatti, in Dolet 2006: 203).

Servindo-se de uma sinédoque para designar o todo pela parte, a dos nombres oratoires, que se referem ao ritmo, Dolet alude ao procedimento retórico da compositio elocutiva. O termo nombre oratoire é a tradução francesa da expressão quintilianana oratorius numerus, 'ritmo', (Quintiliano IX, 4, 57), que, segundo Littré (apud Lausberg 1999: §980), pode ser entendida como "harmonie qui résulte d'un certain arrangement de mots dans la prose et dans les vers" [harmonia que resulta de um certo arranjo de palavras na prosa e nos versos]. Não é bastante que o tradutor conte com o termo próprio e elegante, é mister uma boa conjunção das palavras. Estas devem seguir uma ordem e disposição muito estudadas, devem estar perfeitamente colocadas no lugar que lhes corresponde. Sem esta harmonia, adverte Dolet, "les sentences ne peuvent être graves et avoir leur poids requis et legitime" [as frases não podem ser profundas nem ter o peso requerido e legítimo] (2006: 2002).

O preceito do ritmo vale para todo tipo de texto, tanto para "oradores" como "historiadores". Dolet, assim como o fizeram Bruni e Vives, expressa aqui outra concepção que vem da Antigüidade, a divisão dos escritores em oratores e historici. Historici abarca todo escritor que trata seu tema de forma instrutiva, desapaixonada, caracterizada pelo desejo de informar. A este grupo pertenecem os filósofos e os tratadistas de qualquer assunto. A categoria dos oratores se divide, por sua vez, em oratores e poe- 
tas, sendo que a linha que os separa é determinada pela quantidade e o tipo de ornamentação empregados, mais da ordem da técnica que da substância. Dolet sublinha que todo autor - e considera o tradutor um autor -, orateur ou historiographe,

sans grande observation de nombres n'est rien, et avec iceux il ne peut faillir à avoir bruit en éloquence, si pareillement is est propre en diction et grave en sentences, et en argument subtil (Dolet 2006: 202; 204).

sem grande observância da harmonia, não é nada, mas munido dela não pode deixar de destacar-se em eloqüência, se do mesmo modo possuir propriedade na expressão, profundidade nas sentenças, e sutileza na argumentação (trad. de Goldstein \& Bonatti, in Dolet 2006: 203; 205).

A quinta regra doletiana concerne, pois, à eloqüência. Dolet conclui sua reflexão sobre a tradução tratando da oratio, dando preceitos sobre os nombres oratoires, ou seja, com o mais elevado da retórica elocutiva. A boa tradução não só haverá de cuidar do sentido, da intention de l'auteur [intenção do autor], mas os recriará na língua de chegada com toda sua força e esplendor, produzindo um texto harmônico, rítmico, retórico, literário.

A função da retórica é harmonizar e embelezar a alma e o corpo de cada discurso, torná-lo estilisticamente atrativo, por isso a essência desta ars se encontra na elocutio $^{8}$ [elocução]. E das partes da elocutio, a que mais zela pela estética é o ornatus [ornamentação]. Entre os elementos que, por sua vez, compõem o ornatus, o que toca diretamente à boa composição é a compositio, a correspondência prosaica da versificação poética. A quinta regra doletiana, dos nombres oratoires, aborda precisamente o summum da elocutio, ou seja, o ornatus, com sua compositio, constituída por elementos que dizem respeito à sintaxe e semântica (ordo), à eufonia (iunctura) e ao ritmo (numerus oratorius): 
L'observation des nombres oratoires: c'est à savoir, une liaison et assemblement de dictions avec telle douceur, que non seulement l'âme s'en contente, mais aussi les oreilles en sont toutes râvies, et ne se fâchent jamais d'une telle harmonie de langage (Dolet 2006: 202).

A observância da harmonia do discurso, isto é, de um enlace e união das palavras com tal suavidade que não somente a alma se satisfaça, mas também os ouvidos se encantem e não se cansem jamais de uma tal harmonia de linguagem (trad. de Goldstein \& Bonatti, in Dolet 2006: 203).

Para Dolet, esta última regra é a que definitivamente efetiva e conclui a tradução correta, pois "sans iceux les sentences ne peuvent être graves et avoir leur poids requis et legitime" [sem ela, as sentenças não podem ser graves e ter o peso requerido e legítimo], sem ela, "un auteur n'est rien" [um autor não é nada] (2006: 202; 204). A tradução não pode ser literal, mas 'livre' (liberté), 'criativa' (l'ordre des mots perverti - a ordem das palavras alterada) e profunda (grave). Não se trata somente de traduzir o sentido do texto de partida, ou de reconstruí-lo de qualquer maneira, mas de harmonizar o conjunto para que cada parte ocupe o lugar que lhe corresponde, 'recriar' o texto de partida com correção e eloqüência.

Notas

1. Este texto de Dolet está publicado na Antologia bilíngüe - Clássicos da Teoria da Tradução, Vol. 4: Renascimento, Mauri Furlan (org.), Florianópolis, NUPLITT/ UFSC, 2006. 
2. A proprietas lingüística é um conceito clássico e caríssimo à teoria da linguagem desde a Antigüídade. Fala-se de proprietas uerbi [a propriedade da palavra], referindo-se ao significado próprio de uma palavra, e de proprietas linguae [a propriedade da língua], referindo-se às características e singularidades próprias de uma língua.

3. O termo 'descontrução' aqui empregado não se relaciona à teoria moderna do desconstrutivismo. Desde a Antigüidade e ainda no Renascimento, a teoria da linguagem concebia a linguagem como um processo mental operado segundo o padrão das atividades físicas, sobretudo os métodos de trabalho usados nas construções e na arquitetura. Esta concepção arquitetônica da linguagem possibilitava que se separasse a parte de seu conjunto, a palavra da proposição. A operação comum à construção e ao discurso era a soma das partes - o estruturalismo moderno, por sua vez, olha para o modo de relação entre as partes -; ambos se construíam e desconstruíam parte por parte. Cada componente do discurso era analisado separadamente.

4. As artes eram consideradas atividades ou disciplinas ou ocupações em que o conhecimento teórico estava acoplado às habilidades práticas, algo distinto das scientiae que tratavam exclusivamente do conhecimento especulativo.

5. Estes três textos também foram publicados em edição bilíngüe na 'Antologia do Renascimento' a que nos referimos em nota anterior.

6. A citação de Dolet do texto ciceroniano apresenta algumas variantes frente as edições modernas de Cícero, não obstante, sem impedir a compreensão do conteúdo: animum autem alii animam, ut fere nostri, declarat nomen; nam et agere animam et efflare dicimus et animosos et bene animatos et ex animi sententia; ipse autem animus ab anima dictus est (The Loeb Classical Library, ed. por E. H. Warmington, Londres-Cambridge, Heinemann-Harvard University, 1971).

7. As traduções contemporâneas, que conheço, desta obra de Cícero tampouco conseguiram um texto retórico-literário que desse conta do jogo de palavras latinas animus-anima e as expressões delas derivadas, pelo que, podem parecer às vezes um desvario. A título de exemplo, transcrevo duas traduções que tenho à mão, em catalão e em inglês: "N'hi ha que identifiquen l'ànima amb l'alè, i així ho fa, de fet, la nostra gent, com declara la llíngua: diem "llançar l'últim alè", "expirar", "animós", "ben animat", "en consciència d'ànima"; el mateix mot animus ve d'anima" (trad. de Eduard Valentí, in Cícero, 1948). Ainda maiores problemas apresenta a tradução 
em inglês: "Others however identify soul and breath as we Romans practically do - the name explains this, for we speak of "giving up the ghost" and "expiring" and of "spirited people" and "people of good spirit" and "to the best of one's belief"; moreover the actual word for "soul" has come from the word for "breath" in Latin” (trad. de J. E. King, in Cícero, 1971).

8. A elocutio é a terceira e a mais importante das cinco partes da retórica clássica. A elocutio ou lexis, é a passagem à linguagem das idéias encontradas na inuentio [invenção ou descoberta dos argumentos] e ordenadas na dispositio [ordem dos pensamentos encontrados na inuentio], ao mesmo tempo em que é a estilização do discurso. Dado que a elocutio se refere à formulação lingüística, está ligada à gramática.

\section{Bibliografia}

CARY, Edmond, 1963, Les grands traducteurs français, Genebra, Librairie de l'Université/Georg et Cie.

CHAVY, Paul, 1981, "Les traductions humanistes au début de la Renaissance française: traductions médiévales, traductions modernes", in: Canadian review of comparative literature - special issue: Translation in the Renaissance, VIII, 2, pp. 284-306.

DELISLE, Jean \& WOODSWORTH, Judith, 1995, Les traducteurs dans l'histoire, Ottawa, Université.

DOLET, Étienne, 2006, "La manière de bien traduire d'une langue en autre" in: Furlan, Mauri (org.), Antologia bilingüe. Clássicos da Teoria da Tradução. Vol. 4. Renascimento, Florianópolis, NUPLITT/UFSC, pp. 195-205.

FURLAN, Mauri (org.), 2006, Antologia bilingüe. Clássicos da Teoria da Tradução. Vol. 4. Renascimento, Florianópolis, NUPLITT/UFSC. 
LAUSBERG, Heinrich, 1999, Manual de retórica literaria - fundamentos de una ciencia de la literatura, 3 vols, Madri, Gredos. Trad. de José Pérez Riesco.

LÓPEZ CARRILLO, Rodrigo; MARTÍNEZ DENGRA, Esperanza \& SAN GINÉS AGUILAR, Pedro, 1998, Étienne Dolet y los cinco principios de la traducción, Granada, Comares.

MATTIOLI, Emilio, 1982, "Storia della traduzione e poetiche del tradurre (dall'umanesimo al romanticismo)", in: Processi traduttivi: teorie ed applicazioni. Atti del seminario su "la traduzione", Brescia, La Scuola, pp. 39-58.

NORTON, Glyn P., 1984, The ideology and language of translation in Renaissance France and their humanist antecedents, Ginebra, Droz.

QUINTILIANO, 1979, Institution Oratoire/Institutio oratoria, Paris, Les Belles Lettres.

VEGA, Miguel Ángel, 1994, "Dolet, Du Bellay, Peletier y Sebillet o la traductología francesa del Renacimiento", in: Reflexiones sobre la traducción, Cádiz, Universidad, pp. 721-731.

, 1997, “Apuntes socioculturales de historia de la traducción: del Renacimiento a nuestros días", in: Hieronymus complutensis, 4-5, pp. 71-85. 